\title{
Is There a Role for Chest Computed Tomography in Patients with Primary Spontaneous Pneumothorax?
}

\author{
Iskander Al-Githmi* \\ Department of Surgery, Division of Cardiothoracic Surgery, King Abdulaziz University Hospital, Jeddah, KSA \\ Email: ^ialgithmi@kau.edu.sa
}

How to cite this paper: Al-Githmi, I. (2017) Is There a Role for Chest Computed Tomography in Patients with Primary Spontaneous Pneumothorax? Surgical Science, 8, 429-435.

https://doi.org/10.4236/ss.2017.810047

Received: September 8, 2017

Accepted: October 8, 2017

Published: October 11, 2017

Copyright $\odot 2017$ by author and Scientific Research Publishing Inc. This work is licensed under the Creative Commons Attribution International License (CC BY 4.0).

http://creativecommons.org/licenses/by/4.0/

\section{cc) (7) Open Access}

\begin{abstract}
Background: Primary spontaneous pneumothorax is a relatively common condition in young adults. Although blebs and bullae are frequently found in patients with primary spontaneous pneumothorax, they are very rarely the actual cause of the pneumothorax. Objective: To assess our experience with chest computed tomography evaluation in patients with recurrent spontaneous pneumothorax as compared to their histopathology findings. Study Design: A prospective study analysis. Materials and Methods: From January 2013 to December 2016, 38 consecutive patients with unilateral recurrent spontaneous pneumothorax underwent video-assisted thoracic surgery. Their chest computed tomography scans were reviewed and compared with their histopathology findings. Results: Thirty-six adult patients with unilateral recurrent spontaneous pneumothorax were included; their mean age was 33.9 years, and they all received video-assisted thoracic surgery and mechanical pleurodesis. Blebs or bullae were present in the chest computed tomography scans of fourteen patients (39\%); of those fourteen patients, five (35.7\%) had emphysematous changes in histopathology. Seventeen out of the thirty-six (47\%) had no blebs or bullae in their chest computed tomography scans; of those seventeen patients, ten (59\%) had emphysema like changes and seven (41\%) had blebs in their histopathology studies. The remaining five patients (14\%) had normal chest computed tomography scans. Conclusions: We conclude that preoperative chest computed tomography is not beneficial in every patient with recurrence of primary spontaneous pneumothorax.
\end{abstract}

\section{Keywords}

Primary, Spontaneous Pneumothorax, Recurrence, Computed Tomography, Histopathology 


\section{Introduction}

Primary spontaneous pneumothorax is a relatively common condition in otherwise healthy young adults. The typical patient is young, thin, tall, a cigarette smoker, and has acute chest pain with varying degrees of cough and shortness of breath. The reported incidence of primary spontaneous pneumothorax ranges between " 8 and 28 cases per 100,000 per year for men and 1.2 to 6 cases per 100,000 per year for women [1] [2] [3]". Several studies have reported that chest computed tomography is a useful diagnostic method for the identification of blebs and bullae [4] [5]. Reports have shown that patients with blebs and bullae have a greater risk of pneumothorax than patients without blebs and bullae [6] [7]. Other studies have suggested that pulmonary chest tomography findings (the number and size of blebs and bullae) can predict recurrence of pneumothorax [8]. The aim of this study is to assess our experience of chest computed tomography in recurrence of primary spontaneous pneumothorax compared to histopathology findings.

\section{Materials and Methods}

This prospective study was performed at our institution between January 2013 and December 2016. This study was approved by the local ethics committee, which waived the need for written informed consent. Thirty-six patients [ 6 women (17\%), mean age 32.3 years, 30 men (83\%); mean age 32.1 years] with unilateral primary spontaneous pneumothorax underwent video-assisted thoracic surgery and mechanical pleurodesis $(n=36)$. Preoperative patient demographic data are presented in (Table 1 ).

\subsection{Inclusion Criteria}

All thirty-eight patients admitted with recurrence of unilateral spontaneous

Table 1. Demographic clinical data.

\begin{tabular}{|c|c|c|c|c|}
\hline & $\begin{array}{c}\text { Total } \\
(\mathrm{n}=36)\end{array}$ & $\begin{aligned} \mathrm{CT} & =\mathrm{bleb} \\
(\mathrm{n} & =14)\end{aligned}$ & $\begin{array}{c}\mathrm{CT}=\text { no bleb } \\
(\mathrm{n}=17)\end{array}$ & $P$ value \\
\hline Age $($ mean $\pm S D)$ & $33.89 \pm 15.46$ & $39 \pm 15.94$ & $32.00 \pm 15.58$ & $0.2294^{\mathrm{a}}$ \\
\hline Sex $=$ male & $30(83 \%)$ & $13(93 \%)$ & $13(76 \%)$ & 0.2367 \\
\hline Smoking $=$ yes & $23(64 \%)$ & $9(64 \%)$ & $12(71 \%)$ & 0.7316 \\
\hline Side $=$ left & $22(61 \%)$ & $8(57 \%)$ & $12(71 \%)$ & 0.4575 \\
\hline $\mathrm{CT}=\mathrm{bleb}$ & $14(39 \%)$ & $14(100 \%)$ & $0(0 \%)$ & $<0.001$ \\
\hline $\begin{array}{l}\text { Operative Time (mins) } \\
(\text { mean } \pm \mathrm{SD})\end{array}$ & $103.03 \pm 35.07$ & $109 \pm 37.72$ & $99.41 \pm 33.91$ & 0.4252 \\
\hline Histopathology $=$ bleb & $18(50 \%)$ & $9(64 \%)$ & $7(41 \%)$ & 0.2159 \\
\hline Chest Tube (days) (mean \pm SD) & $4.53 \pm 1.63$ & $4.79 \pm 2.08$ & $4.24 \pm 1.35$ & 0.648 \\
\hline Hospital Stay (days) (mean \pm SD) & $5.42 \pm 2.3$ & $5.43 \pm 2.50$ & $5.12 \pm 1.87$ & 0.8874 \\
\hline
\end{tabular}

A. Calculated using independent two-sample $t$-test. B. Calculated using independent two-sample $t$-test on log scale. Other results calculated using Wilcox on signed-rank test. 
pneumothorax were included in the study. The diagnosis of pneumothorax was based on the evidence of their chest X-rays.

\subsection{Initial Management}

All the patients were initially managed in the emergency department and received thoracic drainage with chest tube size 28 French (F). Suction was added on first resort.

\subsection{Chest Computed Tomography Scans}

During hospitalization, all the patients had high-resolution computed tomography scans of the chest, with slice thickness of five millimeters. The scans were interpreted by different experienced radiologists. Blebs were defined as less than one centimeter in diameter, bullae as more than one centimeter in diameter (Figure 1).

\subsection{Surgical Management}

All patients received video-assisted thoracic surgery, which was performed in standard fashion under general anesthesia with double-lumen endotracheal intubation. Each patient was placed in a lateral decubitus position with the arm abducted to allow the maximum upward displacement of the scapula. A ten millimeter port with a 30 degree telescope, camera attached, was placed in the seventh intercostal space. A utility incision, one inch in length, was made along the anterior axillary line in the fifth intercostal space. The whole lung, particularly

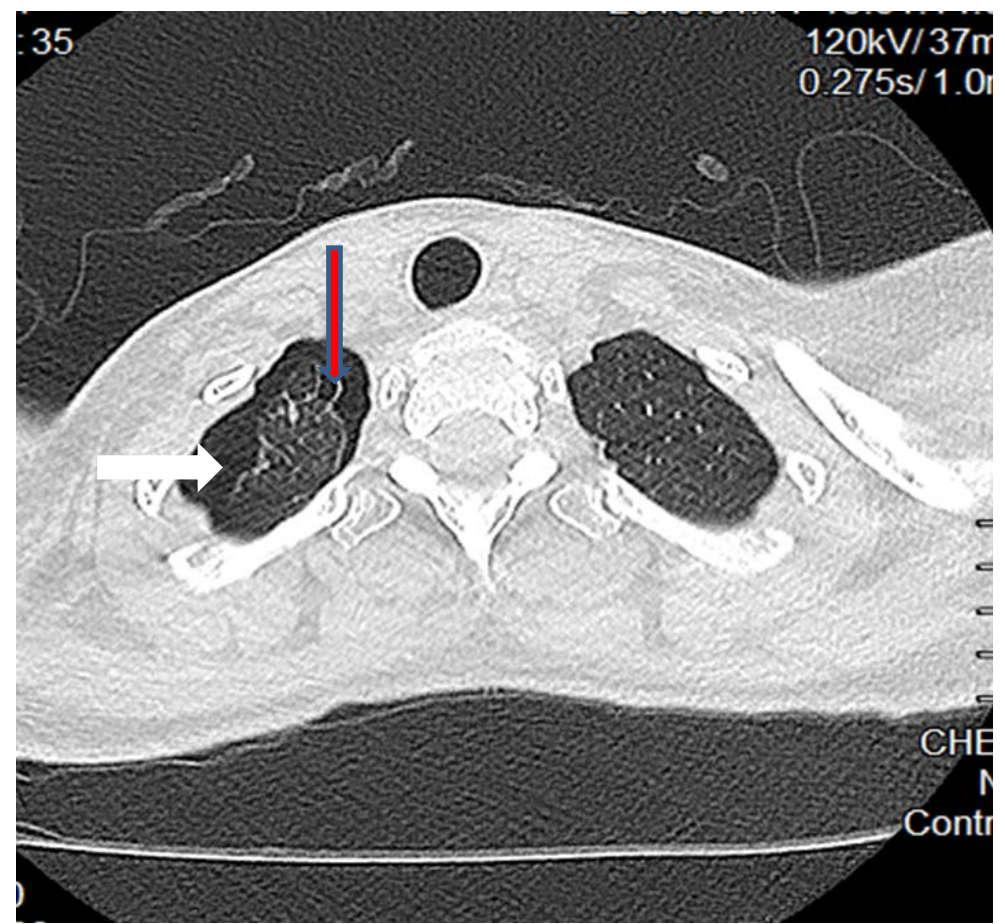

Figure 1. Computed tomographic scan with right apical pneumothorax (white arrow) associated with apical subpleural bleb (red arrow). 
the apical segment of the upper lobe and the superior segments of the lower lobe, was inspected for blebs and bullae. These were resected with a 45 -60-millimeter Endo GIA ${ }^{\text {Tx }}$ (Covedien, Massachusetts, USA). If no blebs or bullae were visible in the lung parenchyma, a blinded resection of the apical segment was performed. The parietal pleural surface was abraded with a scratch pad. A single chest tube size $28 \mathrm{~F}$ was inserted and brought out through the camera port. It was then secured to the chest wall and connected to an underwater seal suction with negative pressure of $-20 \mathrm{~cm} \mathrm{H}_{2} \mathrm{O}$. The chest tube was removed when there was no air leak. The surgical specimens were analyzed by different experienced pathologists. It must be emphasized that this histopathology study was conducted on the apices of lung specimens

\subsection{Patient Follow-Up}

All thirty-six patients were followed up at 6-month intervals in our outpatient clinic over a period of 36 months. At each visit, a chest X-ray was performed.

\subsection{Statistical Analysis}

Statistical analysis was performed using a chi-squared test. The continuous variables were expressed as the mean $\pm \mathrm{SD}$. A $P$ value $<0.05$ was considered statistically significant.

\section{Results}

The clinical data of the thirty-six patients seen in our institution are summarized in (Table 1). There were thirty men (83\%) and six women (17\%). The mean age of the patients was 33.9 years. About $64 \%$ of the patients were smokers. Left-sided spontaneous pneumothorax was identified in twenty-two patients (61\%), and right-sided spontaneous pneumothorax was seen in fourteen patients (39\%). Of the thirty-six patients, fourteen (39\%) were found on a preoperative computed tomography scan to have lung blebs with emphysema like changes. Thus, the sensitivity of computed tomography in the detection of blebs in patients with primary spontaneous pneumothorax was $56 \%$, with positive predictive value of $64 \%$ and negative predictive value of 59\% (Table 2).

Table 2. Comparison between CT scans and histopathology findings.

\begin{tabular}{cccc}
\hline CT scan & Bleb & EC & Total \\
\hline Bleb & 9 & 5 & 14 \\
No Bleb & 7 & 10 & 17 \\
Normal & 2 & 3 & 5 \\
Total & 18 & 18 & 36 \\
Sensitivity & Specificity & Prevalence & PPV \\
$50 \%$ & $56 \%$ & $44 \%$ & $64 \%$ \\
NPV & $59 \%$ & &
\end{tabular}

CT: computed tomography. ELC: emphysema like changes. PPV: positive predictive value. NPV: negative predictive value. 


\section{Discussion}

There is some controversy surrounding the etiology of primary spontaneous pneumothorax. The accepted hypotheses are as follows: first, rupture of a dystrophic apical lesion, known as emphysematous changes [9]; second, air leakage known as "pleural porosity", following peripheral airway inflammation [10], with breakdown of alveoli, air dissection along the interstitium, and containment under the visceral pleura. Smoking has been implicated in the etiological pathway: a smoking habit is associated with a $12 \%$ risk of developing pneumothorax, compared to $0.1 \%$ in nonsmokers [2]. The negative pressure gradient of the pleura increases from the base of the lung to the apex, with the result that the alveoli in the apex are subject to higher distending pressure than those at the base of the lung [11]. In surgical studies, Baronofsky et al. reported that diffuse subpleural bullae predominantly involve lung apices [12]. However, resection of bullae or blebs and dystrophic apical lesion is highly recommended to prevent recurrence. In our study, there was no postoperative recurrence. Of 32 international pneumothorax experts, $85 \%$ recommend recurrence prevention after a second occurrence of primary spontaneous pneumothorax. Thoracoscopic surgical resection and parietal pleural abrasion to prevent primary spontaneous pneumothorax are highly recommended.

The frequency of identifying blebs or bullae in chest computed tomography varies. Guimeraes et al. found apical blebs on $28 \%$ of primary spontaneous pneumothorax chest computed tomography scans and no blebs on the computed tomography scans of 29 matched controls [13]. Studies have shown that more than $80 \%$ of scanned patients, and as many as $79 \%$ of patients who have undergone surgical evaluation, have emphysematous changes [14] [15]. Warner et al. conducted a prospective study on 26 patients who had had computed tomography scans [5]. They showed that blebs and bullae were correlated with recurrence. Sihoe et al. investigated the importance of computed tomography of the chest in selecting patients for prophylactic surgery in order to prevent contralateral recurrence [16]. Contrary to these findings, Ouanes-Besbes et al. could not demonstrate a correlation between computed tomography-based dystrophy severity scoring and recurrence [17].

In our study, we found fourteen patients (39\%) had blebs or bullae on their preoperative computed tomography scan, only, five of whom (35.7\%) had emphysema like changes as compared to histopathology finding. Seventeen out of thirty-six patients (47\%) had no blebs or bullae on their preoperative computed tomography. Ten patients (59\%) had emphysematous changes, and seven patients (41\%) had blebs in their histopathology findings. All patients had surgical resection with mechanical pleurodesis. We observed that all patients benefited from surgery, and there was no postoperative recurrence. Subsequent surgery histopathology revealed blebs or bullae in $41 \%$ of the patients, despite prior normal computed tomography. The preoperative computed tomography scans appeared to have positive predictive value of $64 \%$ and negative predictive value 
of 59\%. The limitations of our study are sample size and challenge of computed tomography interpretation.

\section{Conclusion}

Therefore, based on our data, we conclude that this subset of patients should receive video-assisted thoracic surgical resection. We do not recommend routine preoperative computed tomography of the chest in patients with recurrence of primary spontaneous pneumothorax.

\section{References}

[1] Milton III, L.J., Hepper, N.G. and Offord, K.P. (1979) Incidence of Spontaneous Pneumothorax in Olmsted County Minnesota: 1950-1974. American Review of Respiratory Disease, 120, 1379-1382.

[2] Bense, L., Eklund, G. and Wiman, L.G. (1987) Smoking and the Increased Risk of Contracting Spontaneous Pneumothorax. Chest, 92, 1009-1012. https://doi.org/10.1378/chest.92.6.1009

[3] Henry, N., Arnold, T. and Harvey, J. (2003) BTS Guidelines for the Management of Spontaneous Pneumothorax. Thorax, 58, 1139-1152.

https://doi.org/10.1136/thorax.58.suppl_2.ii39

[4] Mitlehner, W., Friderich, M. and Dissmann, W. (1992) Value of Computer Tomography in the Detection of Bullae and Blebs in Patients with Primary Spontaneous Pneumothorax. Respiration, 59, 221-227. https://doi.org/10.1159/000196062

[5] Warner, B.W., Bailey, B.W. and Shipley, R.T. (1991) Value of Computed Tomography of the Lung in the Management of Spontaneous Pneumothorax. American Journal of Surgery, 162, 39-42. https://doi.org/10.1016/0002-9610(91)90199-N

[6] Choudhary, A.K., Sellars, M.E.K., Wallis, C., et al. (2005) Primary Spontaneous Pneumothorax in Children: The Role of CT in Guiding Management. Clinical Radiology, 60, 508-511. https://doi.org/10.1016/j.crad.2004.12.002

[7] Tamura, M., Ohata, Y. and Sato, H. (2003) Thoracoscopic Appearance of Bilateral Spontaneous Pneumothorax. Chest, 124, 2368-2371. https://doi.org/10.1378/chest.124.6.2368

[8] Sihoe, A.D., Yim, A.P., Lee, T.W., et al. (2000) Can CT Scanning Be Used to Select Patients with Unilateral Primary Spontaneous Pneumothorax for Bilateral Surgery? Chest, 118, 380-383. https://doi.org/10.1378/chest.118.2.380

[9] Noppen, M. and Baumann, M.H. (2003) Pathogenesis and Treatment of Primary Spontaneous Pneumothorax: An Overview. Respiration, 70, 431-438. https://doi.org/10.1159/000072911

[10] Noppen, M., Dekeukeleire, T., Hanon, S., et al. (2006) Fluorescein-Enhanced Autofluorescence Thoracoscopy in Patients with Primary Spontaneous Pneumothorax and Normal Subjects. American Journal of Respiratory and Critical Care Medicine, 174, 26-30. https://doi.org/10.1164/rccm.200602-259OC

[11] West, J.B. (1971) Distribution of Mechanical Stress in the Lung, a Possible Factor in Localisation of Pulmonary Disease. The Lancet, 1, 839-841.

[12] Baronofsky, I.D., Warden, H.G., Kaufman, J.L., Whatley, J. and Hanner, J.M. (1957) Bilateral Therapy for Unilateral Spontaneous Pneumothorax. Journal of Thoracic and Cardiovascular Surgery, 34, 310-322.

[13] Guimaraes, C., Donnelly, L. and Warner, B. (2007) CT Findings for Blebs and Bul- 
lae in Children with Spontaneous Pneumothorax and Comparison with Findings in Normal Age-Matched Controls. Pediatric Radiology, 37, 879-884.

https://doi.org/10.1007/s00247-007-0537-7

[14] Schramel, F., Postmus, P. and Vanderschueren, R. (1997) Current Aspects of Spontaneous Pneumothorax. The European Respiratory Journal, 10, 1372-1379. https://doi.org/10.1183/09031936.97.10061372

[15] Bense, L., Lewander, R., Eklund, G., et al. (1993) Nonsmoking, Non-Alpha 1-Antitrypsin Deficiency-Induced Emphysema in Nonsmokers with Healed Spontaneous Pneumothorax, Identified by Computed Tomography of the Lungs. Chest, 103, 433-438. https://doi.org/10.1378/chest.103.2.433

[16] Sihoe, A.D., Yim, A.P., Lee, T.W., Wan, S., Yuen, E.H., Wan, I.Y. and Arifi, A.A. (2000) Can CT Scanning Be Used to Select Patients with Unilateral Primary Spontaneous Pneumothorax for Bilateral Surgery? Chest, 118, 380-383.

https://doi.org/10.1378/chest.118.2.380

[17] Ouanes-Besbes, L., Goli, M., Knani, J., et al. (2007) Prediction of Recurrent Spontaneous Pneumothorax: CT Scan Findings versus Management Features. Respiratory Medicine, 101, 230-236. 